\title{
Citizens who inject drugs: the 'Fitpack' study
}

\author{
Lenton $\mathrm{S}^{1}$, Kerry $\mathrm{K}^{2}$, Loxley $\mathrm{W}^{1}$, Tan-Quigley $\mathrm{A}^{1}$, Greig $\mathrm{R}^{2}$.
}

${ }^{1}$ National Centre for Research into the Prevention of Drug abuse, Curtin University of Technology \& ${ }^{2}$ Health Department of Western Australia

Correspondence:

Simon Lenton

Research Fellow

National Centre for Research into the Prevention of Drug Abuse

Curtin University of Technology

GPO Box U1987

Perth 6845

Western Australia

Published as: Lenton S, Kerry K, Loxley W, Tan-Quigley A, Greig R. (2000) Citizens who inject drugs: the 'Fitpack' study, International Journal of Drug Policy.11:285-297 


\begin{abstract}
Most injecting drug users have never been in drug treatment yet much research is done on samples with high treatment rates drawn from agency and peer recruited populations. This study accessed drug injectors with little or no prior drug treatment, described their characteristics, BBVI risk behaviours and feedback on services. Its results challenge some stereotypes about citizens who inject drugs. A sample of 511 'hidden' drug injectors, of whom only $28.7 \%$ had any specialist drug treatment agency contact, completed a questionnaire which was distributed with 'Fitpack' needle packs sold through community pharmacies in WA. The mean age of respondents was 26.2 years, $43.4 \%$ were women, $44.3 \%$ were living with their sexual partner, $41.7 \%$ were parents, and $46.4 \%$ were employed, mostly in full time work. In the previous month $61.2 \%$ had injected less frequently than daily. The study accessed a diverse group of drug injectors not typically seen in agency and peer recruited research. They provided useful feedback about how harm reduction strategies among injectors can be improved. However, they also reported higher rates of injecting and sharing than previously found in traditionally recruited samples of injectors which suggests there is no room for complacency regarding the potential for BBVI transmission in this group.
\end{abstract}

Key words: Injecting Drug Users, needle provision, risk behaviour, stereotypes, consumers. 


\section{Introduction}

Most injecting drug users have never been in drug treatment (Frischer, 1992), yet much research is done on samples with high treatment rates drawn from agency and peer recruited populations (Samuels et al., 1992). This is of concern for three main reasons. Firstly, trends in injecting related risk behaviour among the large numbers of 'hidden' Injectors may go undetected which is a concern because higher levels of drug related HIV risk behaviour have been found among non treatment as compared to treatment populations (Donoghoe et al., 1993; Lampinen et al., 1991). Secondly, information about the large numbers of drug injectors who are not known to treatment agencies is important to guide the development of more effective public health responses to the spread of blood-borne viral infections (BBVIs) such as HIV, hepatitis B and hepatitis C (Griffiths et al., 1993). Thirdly, research on agency and peer recruited samples with high 'ever in treatment' rates may reinforce some false public stereotypes about citizens who inject drugs which could undermine strategies which aim to reduce the harm associated with drug injecting.

The present study aimed to develop a new methodology to access basic information on the demographics, drug use, BBVI risk behaviour, and feedback on services from drug injectors not usually accessed by sampling using agency and peer recruitment methods, in order to both inform harm reduction interventions and to challenge some of the false stereotypes about citizens who inject drugs.

\section{$H I V$, injecting drug use and needle provision}

In many western countries, including Australia, one of the main routes of transmission of BBVIs is the sharing of needles and syringes and other injecting equipment (spoons, water, filters, etc.) by Drug injectors (Des Jarlais \& Friedman, 1994). Research has shown that many 
drug injectors have non-injecting sexual partners (Donoghoe, 1992). Sexual contact, and transmission from mother to child, are considered the main routes for spread of HIV infection from injectors to non-injectors. In most western countries where the spread of HIV through drug injectors has emerged as an actual or potential problem, the primary public health strategy has been to make new needles and syringes readily available to injectors (Des Jarlais \& Friedman, 1993).

Western Australia (WA) is thought to have one of the lowest rates of HIV infection among drug injectors in the western world. Largely due to the provision of needles and syringes, the prevalence of HIV among drug injectors in WA is thought to be between 1 and $2 \%$ (Bevan et al., 1996; Health Department of WA, personal communication, 26 October 1993). This compares with rates of between 50 and $60 \%$ among drug injectors in some parts of the USA and Europe (Des Jarlais \& Friedman, 1992; Des Jarlais et al., 1994). Whilst thus far the Australian nation-wide harm reduction strategy has been successful in minimising the spread of HIV through drug injecting, Australia has been less successful with Hepatitis B and C. Wodak and Des Jarlais (1993) noted that new strategies may be required to continue to prevent these epidemics and that this will not be possible without strong community support. Challenging stereotypes which stigmatise and marginalise drug injectors will be an important part of this process.

Since July 1987 the Health Department of WA has administered a program of providing new needles and syringes to drug injectors. Under this program needles and syringes have been provided through The WA AIDS Council's drug outreach van; a gay sauna; through drug treatment agencies, hospitals and nursing posts; and primarily through retail pharmacies (Swensen et al., 1992). Since July 1996 the Perth Aboriginal Medical Service has also 
distributed needles through its outreach van and since 1997 needles have been provided from a fixed site exchange operated by The Western Australian Substance Users Association (WASUA) (Health Department of Western Australia. Personal communication, 4 August 1998).

The 'Fitpack' Program that operates through community pharmacies in WA does not incorporate an exchange component, but rather the emphasis is on providing needles and syringes with a 'safe' disposal container. In WA, at the time of conducting the study, five needles and syringes were sold in each Fitpack. These hard plastic containers are designed to enable used syringes to be 'locked-in' for disposal so that they cannot be removed for re-use or cause injury to children. The container can then be safely disposed of in residential waste. In WA the outside of the Fitpack incorporates harm reduction information. In other Australian states needles are also available in Fitpacks containing three or ten needles, however, at the time of data collection the WA Branch of the Pharmacy Guild of Australia had only endorsed the five packs for sale in this state.

During 1994, the last calendar year prior to data collection, over 1.7 million needles and syringes were provided to drug injectors in WA. By 1997 the over 1.9 million needles and syringes were provided to drug injectors in the state (Government of Western Australia, 1995; Health Department of Western Australia. Personal communication, 4 August 1998), which at the last census in 1996 had a total population of just over 1.7 million people (Australian Bureau of Statistics, 1998). Since at least 1994 87\% of needles and syringes have been provided in the Perth metropolitan area, with over $66 \%$ of the total number provided being sold through community pharmacies, all but a handful of these being sold in Fitpacks (Government of Western Australia, 1995; Health Department of Western Australia. Personal communication, 4 August 1998). The number and dispersion of pharmacies throughout the 
community make them an attractive route to provide needles and syringes to drug injectors. The large proportion of needles distributed through pharmacies in WA is not surprising given the limited number of fixed site and mobile needle exchanges. Additionally for many drug injectors the 'anonymity' provided by a discrete pharmacy service is no doubt attractive. Among the reasons given by people who inject drugs for not using specialised needle exchanges is the fear of being identified as drug users, particularly in the case of those who have not been in treatment, for whom access to needles and education are particularly important (Hawks, 1993). The sale of needles to drug injectors through pharmacies provided an opportunity to access a largely 'hidden' group of injectors who had not previously been accessed through agency and peer recruited samples.

\section{Previous research accessing drug injectors}

There have been two large studies of drug injectors in Australia which have employed agency and peer recruited sampling strategies. The Australian National AIDS and Injecting Drug Use Study (ANAIDUS) was a cross-sectional study of sero-prevalence and HIV risk behaviour among drug injectors which was conducted in 1990 in 4 Australian cities, including Perth (Loxley et al., 1992). The Australian Study of HIV and Injecting Drug Use (ASHIDU), a similar study to ANAIDUS, was conducted in 1994 in the same four cities (Loxley et al., 1995). Never having been in treatment was one stratifying variable in the ASHIDU. Respondents in the WA sample $(n=220)$ were recruited by advertising and snowballing. Recruitment start points included the mobile needle and syringe exchange, drug treatment agencies, youth agencies, educational institutions and interviewer networks. A third (33.6\%) of the Perth ASHIDU sample had never been in formal drug treatment . Only $24.2 \%$ of the sample had completed secondary school, 20.0\% were in some kind of employment, and $32.3 \%$ were on a pension or benefits. Injecting at least once per day in the last month was 
reported by $15.0 \%$ of the sample and in the last month $15.9 \%$ had used a needle after someone else and $15.5 \%$ had passed a needle on after using it (Bevan et al., 1996).

Other Australia studies which have used non-agency based recruitment methodologies have accessed a large proportion of injectors who were not in treatment. However, these have tended to target younger users (Loxley, 1995; Spooner et al., 1992) or users of psychostimulants (Ross et al., 1994) who are often the same group, and are less likely to have been in treatment. In other countries, research comparing drug injectors who attend needle exchanges with those who obtained their needles from other sources, such as pharmacies, has shown that needle exchange attendees had greater knowledge of HIV/AIDS and maintained more harm reduction practices than those who obtained their needles from pharmacies, suggesting that the latter group was an important one to study (Frischer \& Elliot, 1993).

A few studies have used respondent completed questionnaires in an attempt to collect data from drug injectors. In the UK the Anglia and Oxford Regional Health Authority (1995) undertook a mail back survey of drug injectors in 1993 and 1994. The questionnaire comprised seven questions on a single side of one page with gummed sides and a reply paid address on the reverse. In the 1994 survey, 5,000 questionnaires were printed and distributed to those in contact with drug injectors but even if only half the printed questionnaires made it into the hands of people who used injected drugs, the return rate would have been $7.6 \%$. In 1994 a small survey was undertaken in Perth, Western Australia to determine the best way of getting information to those who used the 'Fitpack' needle packs (The AIDS Bureau of the Health Department of WA, unpublished). Brief questionnaires were given to clients of the WA Alcohol and Drug Authority's treatment services. Twenty-three completed questionnaires were returned. As part of this study respondents could make other comments about Fitpacks. 
Many comments referred to Fitpacks being too expensive, and some said this had led to needle sharing. Other comments referred to specific problems with the equipment, and suggested that the negative attitude of some pharmacy staff discouraged needle purchases from pharmacies.

\section{Stereotyping of drug injectors}

For many members of the public illicit drug users, particularly injectors and users of 'hard drugs', are stereotyped as a deviant, homogeneous and separate group from the non-injecting 'general' community. In a survey of the WA public's attitudes to drug injectors and harm reduction strategies, Lenton and Phillips (1997) found that $67 \%$ of respondents believed that most injecting drug users were 'addicts' and $51 \%$ of the sample did not believe that most people who injected illegal drugs were capable of acting responsibly to lessen the risk of HIV spreading. It was hoped that the methodology developed in the current study would access basic demographic and drug use information from drug injectors not usually accessed by sampling using agency and peer recruitment methods to both inform harm reduction interventions and to challenge some of the stereotypes about drug injectors.

\section{Method}

Over a six week period from mid September 1995 Fitpacks sold to drug injectors through 193 community pharmacies state-wide were accompanied by a brief, anonymous questionnaire designed with input from drug injectors and pharmacists. The questionnaire was printed on both sides of a single sheet of paper and incorporated an attached self addressed envelope, the back of which served as a flyer to recruit Fitpack buyers into the project. The top and bottom banners of the flyer were designed to catch their attention by asking if they wanted 'a free Fitpack' and wanted to 'have a say'. The flyer emphasised that the researchers wanted to hear from users of Fitpacks about issues that affected them; offered the study as an opportunity for 
users to correct the general community's unrealistic view of drug injectors; explained that it was designed with input from Fitpack users and had appropriate ethics committee approval; and outlined the mechanism for returning the questionnaire and receiving a free Fitpack for returns through pharmacies.

The questionnaire included 53 questions which covered: demographics; drug treatment history; hepatitis C testing; drug use; and BBVI risk behaviour. Respondents could return completed questionnaires sealed in their attached envelope either through the mail free post, or to participating pharmacies in exchange for a free Fitpack. Three strategies were employed to deal with multiple responders. Respondents were asked not to return more than one questionnaire and the reasons why were explained; it was made easy for multiple responders to respond in a way which was easily identifiable (returning a blank questionnaire); and imbedded unique identifiers (gender, age, postcode and highest education) were used to detect and exclude remaining multiple responders. Pharmacies were paid 50 cents for each questionnaire that they distributed and \$2-60 (the wholesale price of a Fitpack at the time of data collection) for each Fitpack given out in exchange for a completed questionnaire.

In order to make the resulting sample more representative of people who buy Fitpacks, population data for statewide Fitpack sales data were used to weight the data by each of 27 regions. To determine the characteristics of respondents who responded in a certain way on a number of criterion variables, bivariate comparisons were first conducted on a set of key variables to simplify interpretation of the data. To reduce the likelihood of a Type I error a Bonferroni adjustment was employed at an experiment-wise error rate of .05. Subsequently, to determine the relative contribution of the variables which were significant in bivariate comparisons, stepwise backward logistic regression analyses were conducted on these 
variables using unweighted data. To simplify interpretation a simple logistic model was used which did not include interaction terms.

In order to determine the effectiveness of the current study in reaching the group of 'hidden' injectors with little prior contact with specialist drug treatment agencies, results were compared with the Perth data from ASHIDU (Bevan et al., 1996) which was the most recently completed peer and agency recruited interview study.

\section{Results}

The 193 pharmacies which agreed to participate in the study accounted for $60 \%$ of Fitpack sales across the state. These pharmacies reported that 2558 questionnaires were given to Fitpack clients and 511 uncorrupted questionnaires were returned. The vast majority $(94.4 \%)$ of questionnaires were returned through pharmacies in exchange for a free Fitpack. The strategies employed to prevent and identify multiple responders proved effective. Overall, the number of these corrupted returns was small, (10.9\% of all questionnaires returned) and these were easily identified, thus maximising the integrity of the data.

\section{The sample}

The study successfully reached a number of drug injectors with little drug treatment experience. Only $51.0 \%$ of the sample had any prior drug treatment contact (including specialist services and non-specialists such as general practitioners and general hospitals) and only $28.7 \%$ had prior contact with a specialist drug treatment agency (drug detoxification, counselling/treatment, or methadone program). Figure 1. shows that the proportions of the current sample having any prior drug treatment $\left(\chi^{2}=67.1562, \mathrm{df}=1, \mathrm{p}=.0000\right)$ and specialist drug treatment $\left(\chi^{2}=262.0926, \mathrm{df}=1, \mathrm{p}=.0000\right)$ were significantly less than those in the Perth ASHIDU sample (Bevan et al., 1996). 


\section{INSERT FIGURE 1 ABOUT HERE}

Many of the demographic characteristics of this sample are inconsistent with the stereotype of the drug injector held by many in the wider non-injecting community. The mean age of respondents was 26.2 years compared to 27.5years for the Perth ASHIDU sample (Bevan et al., 1996). In the present sample $43.4 \%$ were women, $44.3 \%$ were married or living with their sexual partner and $41.7 \%$ had at least one child, $33.6 \%$ having a child in their care. Figure 2. shows that these proportions were significantly greater than those found in the ASHIDU sample. Just under a quarter (23.8\%) listed senior high school as their highest level of education completed, $22.4 \%$ listed trade or technical school and $6.8 \%$ had completed a university or college course. Only $30.3 \%$ of the sample were unemployed. A larger number of the current respondents were employed (46.4\%) than in the Perth ASHIDU sample $\left(\chi^{2}=226.8518, \mathrm{df}=1, \mathrm{p}=.0000\right)$ and the majority $(66.4 \%)$ of these were in full time employment, most commonly in trades or labouring. Only $7.0 \%$ said they were involved in dealing or other crime. Just over half (53.0\%) the sample earned $\$ 20,000$ or less in the last financial year while $29.4 \%$ earned over $\$ 30,000$ in the same period. Those in the higher income brackets were more likely to be trades persons than those in the lower income levels. Whilst the majority $(59.6 \%)$ of the sample lived in rental accommodation, $16.8 \%$ owned or were buying their place of residence and $15.4 \%$ lived in their parent's home. More than one in ten $(12.7 \%)$ of the sample were from outside the metropolitan area. 
INSERT FIGURE 2 ABOUT HERE

\section{Drug injecting behaviour}

The mean age at which respondents first injected a drug was 19.0 years. The mean number of years the sample had been injecting was 7.1 years, compared to 9.2 years for subjects in the ASHIDU sample $\left(\chi^{2}=71.1145, \mathrm{df}=3, \mathrm{p}=.0000\right)$ (Bevan et al., 1996) which may in part be due to the younger average age of the present sample. While the majority $(61.2 \%)$ had injected less frequently than daily over the previous month, this was fewer than the $85.0 \%$ of subjects in the Perth ASHIDU sample $\left(\chi^{2}=210.3973, \mathrm{df}=1, \mathrm{p}=.0000\right)$. One in four $(24.2 \%)$ respondents injected once a week or less often.

Amphetamines were injected by most respondents (72.9\%) in the previous month, followed by heroin $(50.8 \%)$ and other opiates (excluding heroin, methadone, homebake - heroin and morphine illicitly synthesised from codeine-based pharmaceuticals (Reynolds et al., 1997) (12.8\%). Drugs injected were coded into depressants, stimulants or others. 'Depressants' included: heroin, homebake, methadone, other opiates (eg morphine), tranquillisers (including benzodiazepines) and alcohol. Amphetamine and cocaine were the only stimulant drugs injected. Over the previous month two fifths $(42.6 \%)$ of respondents only injected stimulants, and just under a third (30.7\%) injected drugs from both stimulants and depressants. Just over a quarter $(26.7 \%)$ of respondents stated that over the previous month they had only injected depressants. 
The majority $(80.7 \%)$ of respondents reported that they usually injected in their own home, just over a quarter (29.4\%) in a friend's home and just over one in five $(22.1 \%)$ identified a car as a place where they usually injected. Those respondents who injected 'outside' (either car, park / beach / street, or pub / club) were more likely to report injecting depressants with the needles in the Fitpack $(\mathrm{OR}=3.52,95 \% \mathrm{CI}=2.23,5.56)$ and to have shared needles in the previous month $(\mathrm{OR}=2.69,95 \% \mathrm{CI}=1.76,4.12)$.

Most respondents reported that they disposed of their used needles by locking them into the Fitpack (68.3\%). Just under a third disposed of the used fits quickly (31.6\%), forced the needle into the barrel $(30.9 \%)$, saved their used fits for reuse later $(29.3 \%)$ or threw them into the household rubbish bin $(29.3 \%)$.

\section{Sharing and re-using equipment}

In the previous month $27.7 \%$ had used a needle after someone else, compared to $15.9 \%$ of the Perth ASHIDU sample (Bevan et al., 1996) $\left(\chi^{2}=53.1750, \mathrm{df}=1, \mathrm{p}=.0000\right)$. Overall, $39.9 \%$ of the sample had shared (either passed on and/or received) a needle in the previous month. Those who shared were more likely to have shared other equipment (eg. spoon, filter, water, tourniquet) over the previous month $(\mathrm{OR}=5.95,95 \% \mathrm{CI}=3.75,9.36)$. They were also more likely to be under 26 years of age $(\mathrm{OR}=1.97,95 \% \mathrm{CI}=1.29,3.02)$ and to have injected at least daily $(\mathrm{OR}=1.87,95 \% \mathrm{CI}=1.22,2.86)$. Most of those who shared needles in the previous month did so with their sexual partner $(59.1 \%)$ or a close friend $(39.6 \%)$. Over half the sample $58.5 \%$ reported that they had shared other injecting equipment (eg. spoon, filter, water, tourniquet) in the previous month. On at least one occasion in the previous 12 months over a third $(35.6 \%)$ of the sample had shared a needle because they did not have enough money to 
buy a Fitpack. Those who had done this were more likely to have shared other injecting equipment in the previous month $(\mathrm{OR}=2.98,95 \% \mathrm{CI}=1.77,5.00)$.

Approximately forty percent $(39.1 \%)$ of the sample re-used their own needles from the Fitpack. Those who did so were more likely to be married or living with their sexual partner $(\mathrm{OR}=2.34,95 \% \mathrm{CI}=1.57,3.52)$ to have shared needles in the previous month $(\mathrm{OR}=1.57$, $95 \% \mathrm{CI}=1.01,2.42$ ), and to have shared other injecting equipment in the previous month $(\mathrm{OR}=1.75,95 \% \mathrm{CI}=1.11,2.73)$. The most common reasons for re-use were concern with expense and economy of re-use $(26.7 \%)$, and that they did not have enough needles and syringes for the number of injecting sessions or people who were using (26.5\%). Other reasons included not having enough money for new needles $(14.3 \%)$, the belief that 'using a needle twice was OK' (12.9\%), and access problems (eg. after hours) (12.6\%).

\section{Hepatitis C testing}

The majority (64.9\%) of the sample reported that they had been tested for hepatitis C. Those tested were more likely to have had contact with a specialist drug treatment agency $(\mathrm{OR}=2.87$, $95 \% \mathrm{CI}=1.78,4.63)$, to have children $(\mathrm{OR}=1.57,95 \% \mathrm{CI}=1.05,2.37)$, and to have been charged with a drug offence $(\mathrm{OR}=1.51,95 \% \mathrm{CI}=1.01,2.26)$. A quarter $(25.2 \%)$ of those tested reported that they had a positive result, substantially fewer than the $42.3 \%$ in Bevan et al. (1996) $\left(\chi^{2}=34.4465, \mathrm{df}=1, \mathrm{p}=.0000\right)$. Those in the current study who reported they were positive for hepatitis $\mathrm{C}$ and were aware of the result, were more likely to have been injecting for 10 years or more $(\mathrm{OR}=6.48,95 \% \mathrm{CI}=2.84,14.8)$, to have said that depressants were injected with needles in this Fitpack $(\mathrm{OR}=4.33,95 \% \mathrm{CI}=1.87,10.0)$, and to have had prior contact with a specialist drug agency $(\mathrm{OR}=2.73,95 \% \mathrm{CI}=1.05,7.07)$. 


\section{Feedback on the Fitpack scheme}

Most respondents wanted to see sterile water (75.7\%) and swabs (65.6\%) sold with Fitpacks, and $79.7 \%$ wanted Fitpacks available in vending machines. Those who wanted to see Fitpacks available in vending machines were more likely to have said depressants were injected with the needles in the Fitpack $(\mathrm{OR}=2.16,95 \% \mathrm{CI}=1.26,3.70)$, to be under 18 years of age when they first injected $(\mathrm{OR}=2.09,95 \% \mathrm{CI}=1.23,3.53)$, and to have injected at least daily in the previous month $(\mathrm{OR}=1.87,95 \% \mathrm{CI}=1.05,3.30)$. Whilst $28.3 \%$ of respondents wanted to see three needle Fitpacks available in WA, $75.0 \%$ wanted to see ten needle packs available.

Thirty six percent of the sample reported that they never had problems buying Fitpacks, $29.0 \%$ had problems rarely and $34.7 \%$ had problems at least sometimes. The most common problems specified by those in the latter group perceived negative attitude of pharmacy staff (64.1\%) and unavailability (41.0\%), of needles (for example after hours), while only $6.2 \%$ identified price as an issue. Three quarters $(75.5 \%)$ of the sample said they had problems with the Fitpacks themselves or the needles in them. Over two fifths $(42.2 \%)$ of this group identified needles that were loose, bent, blunt or broken, and $31.9 \%$ said that needles had been locked into the Fitpack prior to purchase. Half (49.5\%) of the sample had purchased more than five Fitpacks in the previous month.

The vast majority $(85.5 \%)$ of respondents paid between $\$ 4.05$ and $\$ 5.00$ for the Fitpack (range $\$ 3-00$ to $\$ 10-00$ ). At the time of data collection the recommended retail price for a Fitpack was $\$ 3.60$. Three quarters $(75.7 \%)$ thought that the price they paid for it was not fair, with $\$ 4-49$ being the average price paid by those who thought the price was fair. 
The majority $(81.9 \%)$ of respondents used the Fitpack for the first time within an hour of buying it. A third (33.0\%) of the sample had used the Fitpack less than 10 minutes after purchase. Those who injected within 10 minutes of purchase were more likely to have first injected at less than 18 years of age $(\mathrm{OR}=2.18,95 \% \mathrm{CI}=1.41,3.38)$ and to be under 26 years of age $(\mathrm{OR}=1.84,95 \% \mathrm{CI}=1.14,2.94)$. They were also more likely in the last month to have injected at least daily $(\mathrm{OR}=2.53,95 \% \mathrm{CI}=1.63,3.92)$, shared needles $(\mathrm{OR}=1.85,95 \% \mathrm{CI}=1.22$, $2.82)$ and injected depressants $(\mathrm{OR}=1.81,95 \% \mathrm{CI}=1.13,2.87)$. In $86.9 \%$ of cases the Fitpack was used by more than one person and $40.3 \%$ said that it was used by more than three people, those who did this being more likely to have first injected at less than 18 years of age $(\mathrm{OR}=1.82,95 \% \mathrm{CI}=1.26,2.63)$. Just over a quarter $(27.6 \%)$ of respondents said that the Fitpack was only used on one injecting session, and $34.3 \%$ use it on only two sessions.

\section{Sexual behaviour}

A majority (58.1\%) of respondents had sexual intercourse with only one person in the previous month. About a quarter of respondents (24.7\%) had not engaged in vaginal / anal sexual intercourse in that period of time. The majority $(64.1 \%)$ of those who had intercourse in the previous month did not use condoms at all. Only $12.6 \%$ of the sample reported using condoms every time they had sexual intercourse in the previous month, compared to $21.2 \%$ in the Bevan et al. (1996). This difference may be explained by the larger number of subjects married or living with their sexual partner in the current study.

\section{Discussion}

It is not possible to say that the resulting sample in this study was representative of the sample of all drug injectors. The questionnaire employed in this study served as it's own recruitment flyer. However, it is not possible to say how many of the questionnaires that pharmacists said 
were distributed were actually received by Fitpack clients who had not previously been given one. One in five of the questionnaires sent to pharmacists were returned completed by Fitpack users. This compares favourably with the only known similar study (Anglia and Oxford Regional Health Authority (1995) which, while not employing an inducement for return, resulted in less than $7.6 \%$ of questionnaires distributed, being returned. The sample was possibly more representative of drug users who buy their needles through pharmacies than it was of drug injectors as a whole. In as much as the bulk of needle provision to injectors in WA is through pharmacy sales rather than other sources (eg needle exchange), this group is an important one to study. The data collected in the current study are an addition to the body of knowledge which is based on studies using other recruitment methodologies such as agency and peer based methods.

The purpose of the comparisons with the agency and peer recruited sample of Bevan et al. (1996) was not to show that any one sample was more representative than the other, nor that together these samples represented the total population of drug injectors. Different recruitment strategies would be expected to result in different sub-populations being sampled. While the differences between the samples may largely reflect the means employed to recruit them, they serve to emphasise the need to employ a variety of such means if a more representative picture of drug injectors is to be obtained. Different methodologies have their advantages and disadvantages. The face to face interview possible with agency and peer recruited samples allows a level of detail about drug using to be studied in a way that is not possible in a self completion 'mail back' survey such as the one described here. However, one of the aims of the current study was to reach the 'hidden' population of drug injectors with no or little drug treatment experience. This group is one which has been anecdotally 'known about', as long as research on drug injecting has been carried out, yet it is a group about which 
there has been little data collected. The study has successfully accessed a large number of respondents from this group. Only $28.7 \%$ had any prior contact with a specialist drug treatment agency. More than half $(61.2 \%)$ of the sample injected less often than once per day suggesting that many were not physically dependent of the drugs they were injecting. Only a small minority $(7.0 \%)$ stated that they were involved in drug dealing or other crime as a form of income. Even if this is an underestimate, it suggests that while much acquisitive crime may be drug related, only a small proportion of the group accessed in this study were involved in crime other than that of drug possession and use.

The greater proportion of daily injectors in the current study compared to the ASHIDU study may be due in part to the higher treatment rates in latter. However, the higher rates of injecting and needles and syringes sharing found in this study compared to those using more traditional agency and peer recruited methods supports similar findings from overseas studies (Donoghoe et al., 1993; Lampinen et al., 1991) and suggests that there may be a higher level of risk behaviour among 'hidden' injectors with little contact with drug treatment agencies. This risk behaviour appears to be occurring below our current epidemiological radar and points to a need for ongoing monitoring of this population which is not reached by agency and peer based research. It may also be that the anonymity provided by the current methodology minimises the impact of any social desirability in response styles which is more likely to be evident in face-to-face interviews, particularly on items concerning frequency of injecting and needle sharing. Respondents may be more candid in admitting to needle sharing in a research paradigm where they feel less exposed or judged. The importance of length of drug injecting career in predicting hepatitis C positivity was consistent with earlier research (Bevan et al., 1996; Crofts et al., 1993; Loxley et al., 1995). 
The results of the study suggested that barriers to needle and syringe access and quality control issues needed to be addressed. The availability of Fitpacks in vending machines may address problems of availability after hours. The experiences of some respondents in approaching pharmacy staff to purchase Fitpacks suggested that as part of on-going professional education pharmacy staff should be offered the opportunity to consider illicit drug use issues, their attitudes to the sale of needles, and the evidence for needle provision as an effective strategy to reduce the spread of BBVIs. The feedback from Fitpack users also suggested that companies involved in the supply of needles, Fitpacks and their packaging should review quality control issues. This feedback has informed quality reviews subsequently undertaken by the suppliers and packers of Fitpacks.

The cost of needles and the numbers sold per pack appeared to lead to needle re-use and sharing by some injectors. These findings suggested review of the pricing of Fitpacks, the sizes available (as described above), and the inclusion of other injecting equipment. As of August 1998, needle packs containing three and five needles and different combinations of spoons, water ampoules and swabs were made available in WA pharmacies (Health Department of Western Australia. Personal communication, 4 August 1998). The findings also suggested that drug injectors may need education about the risks of re-use of own equipment. The harm reduction message 'a new fit for every hit' (a new needle for every injection) does not seem to be having the desired impact with a large minority of these respondents.

\section{Conclusions}

The methodology developed and applied in this study accessed a group of drug injectors not typically seen in agency and peer recruited research. They were a diverse group and show that 
there are many drug injectors who do not fit the negative stereotype held by some in the community who do not inject drugs. They provided useful feedback about how harm reduction strategies for injectors could be improved. However, they also reported higher rates of injecting and sharing than previously found in traditionally recruited samples of injectors which suggests there is no room for complacency. Similar methodology could be applied in other locations to access drug injectors who do not come into contact with specialist drug treatment agencies. It is also able to reach rural drug injectors who have often been neglected in research which has recruited injectors in large population centres.

\section{Different strokes for different folks}

This study reached a heterogeneous group of drug injectors who challenged the 'them and us' view which marginalises and stigmatises many drug injectors. Challenging stereotypes and stigma is likely to be important in further supporting efforts to prevent the spread of blood borne viruses such as HIV, hepatitis B and hepatitis C. Strategies need to be implemented which involve drug injectors and address their wide diversity. While some injectors are affluent others are financially poor. While many can afford the price of a five needle Fitpack, at times others may not and as a result may share. Whilst most will inject at home, others will inject in a car or a public toilet without access to swabs or sterile water. While some may not have problems accessing clean equipment, others may be less likely to share if needles are available in vending machines. Providing better blood-borne virus protection for the public, be they injectors, their children, or sexual partners, means providing a range of alternatives and choices which reflect the variety of life situations and needs of this varied group of citizens who inject drugs. 


\section{Fitpack buyers as consumers}

The purchasers and users of Fitpacks who were the respondents in this study are consumers of a product. This study gave them an opportunity to provide feedback to the manufacturers and retailers of this product and the public health officials who have responsibility for developing and maintaining effective strategies to prevent the spread of blood-borne viral infections such as HIV, hepatitis B and hepatitis C. It has shown that many drug injectors are interested in having a say about issues that affect them and they possess information which is valuable and should be considered by policy makers, health bureaucrats, pharmacists, researchers and others. Repeating the methodology at regular intervals may provide useful information on trends in the characteristics of these injectors and their feedback on the services and equipment provided to reduce injecting-related harm.

\section{No room for complacency}

It is of concern that the 'hidden' drug injectors whom this study has reached reported higher rates of injecting and needle sharing than has been found in studies using agency and peer recruited sampling techniques with higher ever in treatment rates. Thus far in Australia we may have prevented the 'second wave' of HIV infection among drug injectors and through them to people who do not inject. However, while there is evidence that rates of needle sharing have reduced among well researched populations of injectors, these data suggest that needle sharing and unprotected sex occurs more often among this under researched group. These data warn against complacency in prevention of HIV, hepatitis and other, perhaps yet to be discovered, blood-borne viral infections among and from drug injectors.

[5 928 words] 
Citizens who inject drugs: the Fitpack study

\section{Acknowledgments}

Thanks go to all the people who were involved in the study and in particular the following: Users of Fitpacks who filled out and returned the questionnaire, the drug injectors and pharmacy staff who contributed to the project design and implementation. This project was funded by a Commonwealth AIDS Research Grant (Australia) and was endorsed and supported by the Health Department of WA, the Pharmaceutical Council of WA and The Australian Pharmacy Guild (WA Branch). Copies of the full report are available from the first author. 


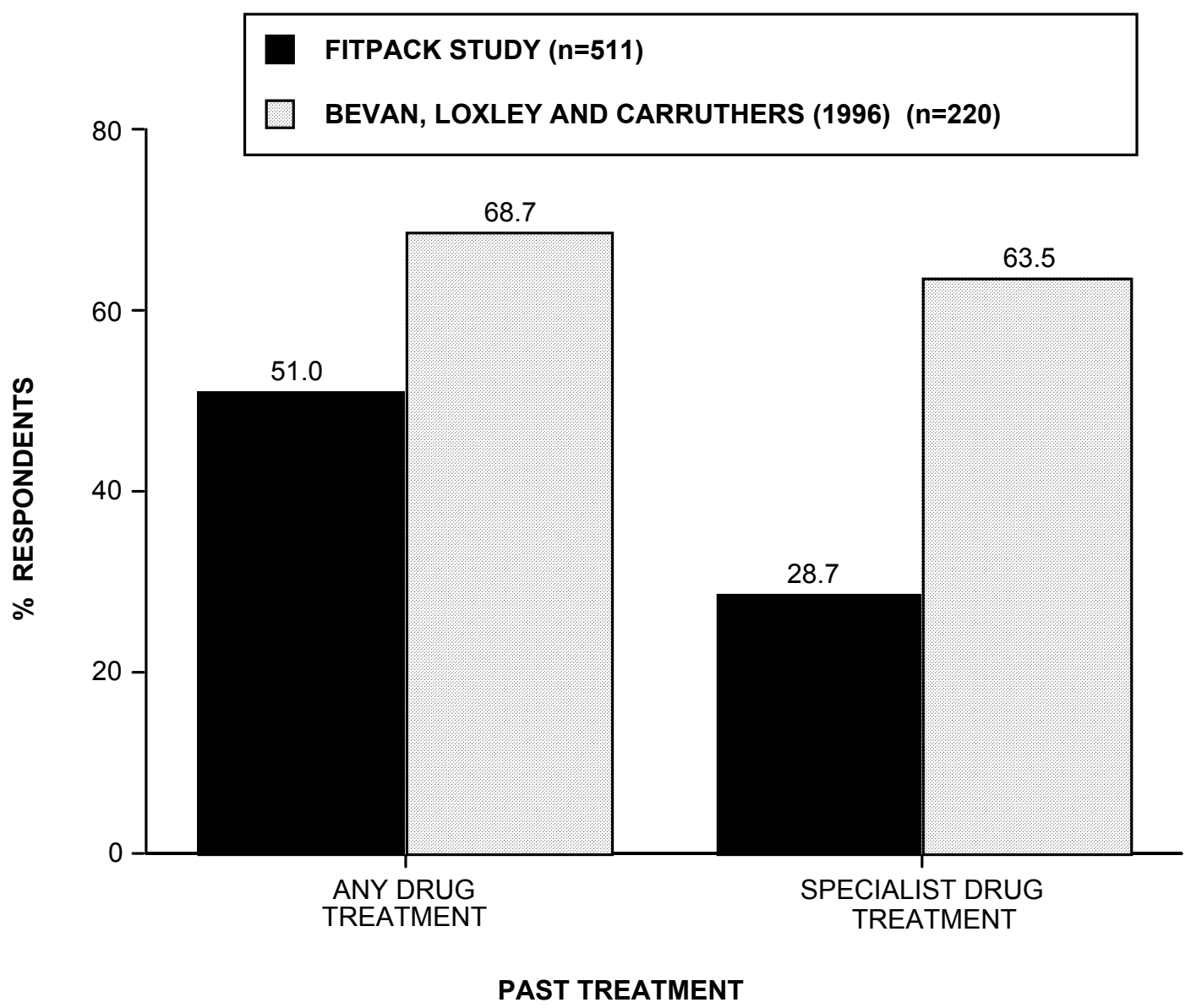

(All the differences between the studies are significant at $p<.001$ )

FIGURE 1:

Comparison of past treatment with Perth ASHIDU data 


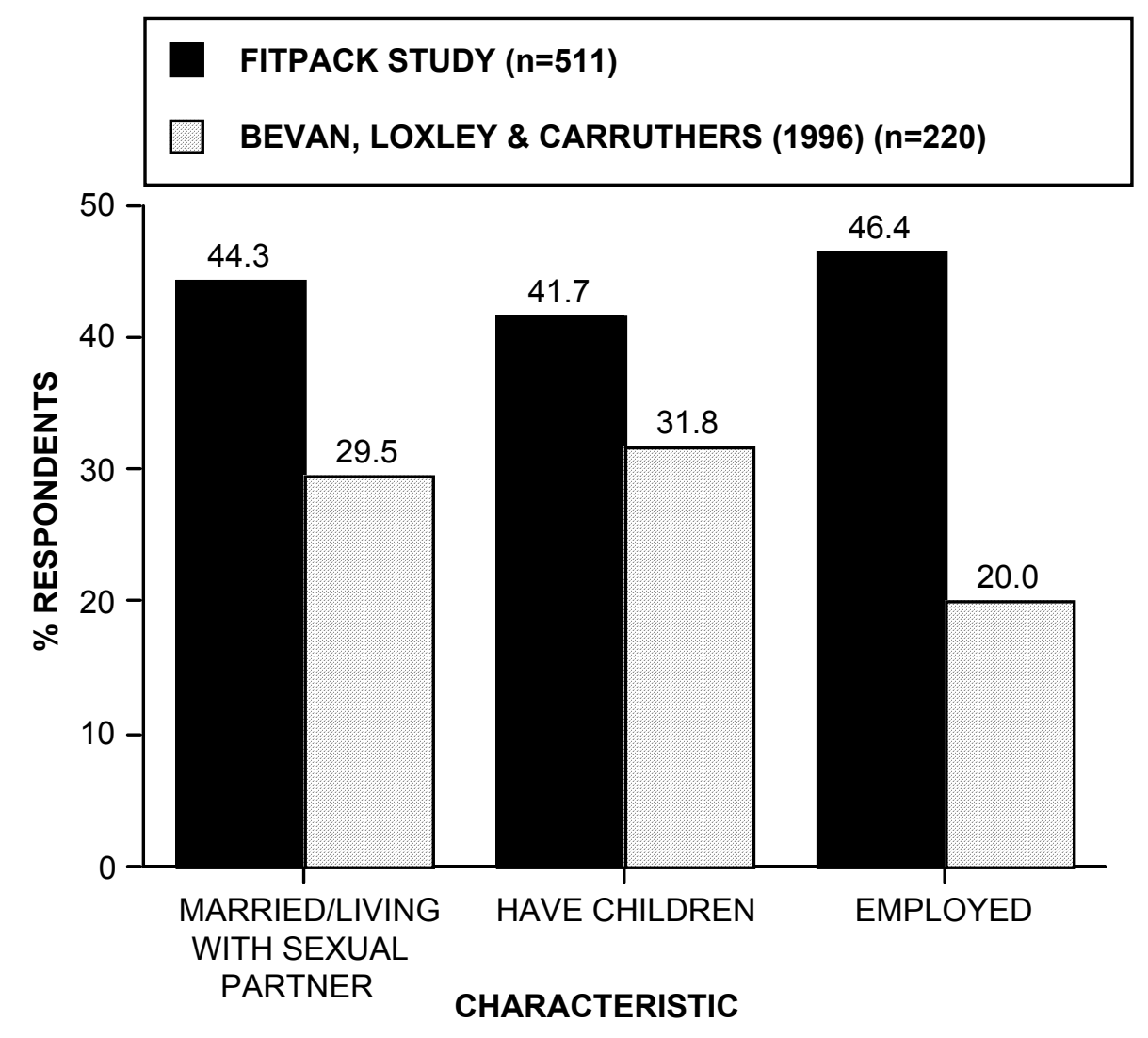

(All differences between the studies are significant at $p<.05$ )

FIGURE 2:

Comparison of key demographics with Perth ASHIDU data 


\section{References}

This article was published in International Journal of Drug Policy,11(4),Lenton S, Kerry K, Loxley W, Tan-Quigley A, Greig R, Laws applying to minor cannabis offences in Australia and their evaluation, Pages No. 285-297, Copyright 2000, and is posted with permission from Elsevier

AIDS Bureau, Health Department of Western Australia (unpublished) Report on Fitpack survey, February 1994.

Anglia and Oxford Regional Health Authority, 1995. Sharing injecting equipment in East Anglia: report of the survey in East Anglia in 1994 (Cambridge, NHS Executive).

Anglia and Oxford Regional Health Authority. Personal communication, 20 June 1995.

Australian Bureau of Statistics 1996 Census of Population and Housing - Community Profiles http://www.abs.gov.au/websitedbs/D3310108.NSF?OpenDatabase (Accessed 11 April 1998)

Bevan, J., Loxley, W. \& Carruthers, S., 1996. Getting on and getting off in Perth 1994: Report of the Australian study of HIV and injecting drug use (ASHIDU) (Perth, National Centre for Research into the Prevention of Drug Abuse).

Crofts, N., Hopper, J.L., Bowden, D.S., Breschkin, A.M., Milner, R. \& Locarnini, S.A., 1993. Hepatitis $\mathrm{C}$ virus infection among a cohort of Victorian injecting drug users, Medical Journal of Australia, 159, 237-241.

Des Jarlais, D.C \& Freidman, S.R., 1993. AIDS, injecting drug use and harm reduction, in: Heather, N., Wodak, A., Nadelmann, E., O'Hare, P., (Eds) Psychoactive drugs and harm reduction from faith to science, pp.297-309 (London, Whurr).

Des Jarlais, D.C. \& Freidman, S.R., 1992. AIDS and access to sterile drug injecting equipment, Annals of the American Academy of Political and Social Science, 521, 42-65.

Des Jarlais, D.C. \& Friedman, S.R., 1994. AIDS and the use of injected drugs, Scientific American. February, 56 - 62.

Des Jarlais, D.C., Friedman, S.R., Sotheran, J., Wenston, J., Marmor, M., Yancovitz, S. et al., 1994. Continuity and change within an HIV epidemic: IDUs in New York City 1984 through 1992, Journal of the American Medical Association, 271, 121-7, 1994. 
Donoghoe M.C., Rhodes, T.J., Hunter, G.M. \& Stimson, G.V., 1993. HIV testing and unreported HIV positivity among drug injectors in London, AIDS, 7, 1105-1111.

Donoghoe, M., 1992. Sex, HIV and the drug user, British Journal of Addiction ; 87: 405 416.

Frischer, M. \& Elliott, L., 1993. Discriminating needle exchange attenders from nonattenders, Addiction, 88, $691-687$.

Frischer. M., 1992. Estimated prevalence of injecting drug use in Glasgow, British Journal of Addiction, 87, 235-243.

Government of Western Australia, 1995. Protecting the Community: Report of the Task Force on Drug Abuse (Perth, Government of Western Australia).

Griffiths, P., Gossop, M., Powis, B. \& Strang, J., 1993. Reaching hidden populations of drug injectors by privileged access interviewers: methodological and practical issues, Addiction, $88,1617-1626$.

Hawks, D., 1993. Impediments to the global adoption of harm- reduction policies, in Heather, N., Wodak, A., Nadelmann, E. \& O'Hare, P. Psychoactive drugs and Harm Reduction: From Faith to Science (London, Whurr).

Health Department of Western Australia. Personal communication, 26 October 1993.

Health Department of Western Australia. Personal communication, 4 August 1998.

Lampinen, T.M., Joo, E., Seweryn, S., Hershow, R.C. \& Weibel, W., 1991. HIV seropositivity in community-recruited and drug treatment samples of injecting drug users, AIDS, 6, 123-126.

Lenton, S. \& Phillips, M., 1997. Mobilizing public support for providing needles to drug injectors, International Journal of Drug Policy 8, 101-110.

Loxley, W., 1995. Young injecting drug users and the risk of HIV/AIDS: psychosocial and environmental constraints on safer drug use and injecting behaviour ( $\mathrm{PhD}$ Thesis, Perth, Curtin University of Technology). 
Loxley, W., Carruthers, S. \& Bevan, J., 1995. In the same vein: First report of the Australian study of HIV and injecting drug use (ASHIDU) (Perth, National Centre for Research into the Prevention of Drug Abuse, Curtin University of Technology).

Loxley, W., McDonald, C. \& Marsh, A., 1992. The Australian AIDS and injecting drug use study, Perth, 1990 (Perth, National Centre for Research into the Prevention of Drug Abuse, Curtin University of Technology).

Reynolds, J., Lenton, S., Charlton, M. \& Caporn, J., 1997. Shopping, baking and Using: The manufacture, use, and problems associated with the use of heroin made in the home from codeine based pharmaceuticals. In Harm Reduction: A new direction for drug policies and programs, P.A. Erikson, D.A. Riley, Y.T. Cheung and P.A. O'Hare (eds.), Toronto, University of Toronto Press, pp. 324-339.

Ross, J., Cohen, C., Darke, S., Hando, J. \& Hall, W., 1994. Transitions between routes of administration and correlates of injecting amongst regular amphetamine users in Sydney. National Drug and Alcohol Research Centre, Monograph No. 18, (Sydney, University of New South Wales).

Samuels, J.F., Vlahov, D., Anthony, J.C. \& Chaisson, R.E., 1992. Measurement of HIV risk behaviours among intraveneous drug users, British Journal of Addiction, 87, 417-428.

Spooner, C., Flaherty, B. \& Hommel, P., 1992. Results of a street intercept survey of young illicit drug users in Sydney (Sydney, Drug and Alcohol Directorate, NSW Health Department, In House Report Series No. 92-1).

Swensen, G., Westlund, G. \& Baker, M., 1992. Sales of Needles and Syringes in WA - The SS5 Pack Project (Perth, Health Department Of Western Australia).

Wodak A. \& Des Jarlais D.C., 1993. Strategies for the prevention of HIV infection among and from injecting drug users, Bulletin on Narcotics, 45, 47-60. 